ISSN 1112-9867

\title{
THE EFFECTIVENESS OF MULTILEVEL CLASSIFICATION SYSTEM FOR SPORT PSYCHOLOGY (MCS-SP) MODEL FOR ATHLETES PERFORMANCE FUNCTIONAL EVALUATION
}

\author{
M. K. N. Haziyanti ${ }^{*}$, A. R. M. Shariff and Y. Ahmad \\ Faculty of Sports Science and Coaching, Universiti Pendidikan Sultan Idris, Tanjung Malim, \\ Perak, Malaysia
}

Published online: 10 November 2017

\begin{abstract}
This study attempted to distinguish issues and athletes' problem into the category of performance function based on Multilevel Classification System for Sport Psychology (MCS-SP). In this study, athletes' performance function were devided into Performance Development (PD) $(n=54)$ and Performance Dysfunction (Pdy) (n=43). Using Five Facet Mindfulness Questionnaire (FFMQ) and Young Schema Questionnaire (YSQ-S3), the overall level of mindfulness skills and thinking schemes were moderate. PD athletes were standing out significantly in mindfulness skills and few elements of thinking schemes such as self-sacrificing, unrelenting standards, and entitlement. Meanwhile, Pdy athletes were more likely to be in other side of thinking schemes elements. It can be seen that MCS-SP can be used as a standard reference for identifying athletes' performance functional status and planning for better psychological interventions.
\end{abstract}

Keywords: Multilevel Classification System for Sport Psychology (MCS-SP), Performance Function, Performance Development (PD), Performance Dysfunction (Pdy), MASUM athlete

Author Correspondence, e-mail: nur.haziyanti@fsskj.upsi.edu.my

doi: http://dx.doi.org/10.4314/jfas.v9i6s.100 


\section{INTRODUCTION}

Applied Sport Psychology provides many ideas about psychological skills training (PST) methods to enhance athletes' performance $[1,2,3]$. However, due to the complexity of sport behavior characteristics, Clinical Sport Psychology has coming to play a role to provide a standard method to identify the functionality of an athletes' performance. In the context of athletes' performance enhancement, the goal of PST is to increase fun and to achieve greater self-satisfaction in sport and physical activity [4]. The main factors affecting PST is the expected result of psychological skills and the method of training or techniques used to get the expected psychological skill result [5]. A well-planned PST programmes can affect an athlete performance [6].

Athletes' readiness to participate in PST programme is very important to ensure the achievement of the training programme objectives. Applied Sport Psychology must have more comprehensive scope to cover issues related to the well-being and development of athletes [7, 8, 9]. Although Applied Sport Psychology has contributed a lot in introducing technique and PST that can be used to enhance athlete performance, but there is lack of formal way to distinguish the issues and problems of athletes [10]. Athletes' issues and problems will affect their willingness to participate in PST programme and thus should bring to attention to ensure that the objectives of PST programme in improving athlete performance can be achieved [11]. Thus, Multilevel Classification System for Sport Psychology (MCS-SP) has been proposed to select athletes' category based on their readiness to undergo PST [11]. MCS-SP model was introduced through Sport Psychology Clinical as a standard reference to determine the classification of athletes based on their performance function which consist of Performance Development (PD), Performance Dysfunction (Pdy), Performance Impairment (PI) and Performance Termination (PT) categories.

Semi-Structured Interview of MCS-SP is one of the valuation methods used to determine the classification of the athletes performance. The concept of semi-structured means the process by which a number of critical domains assessed systematically in order to get information about issues or problems, personal history and performance, and the history of the issue. The period of good interview is between 60 to 90 minutes. In addition, a simpler measuring tool may also be used such as Performance Classification Questionnaire (PCQ) [12]. However, the goal of 
PCQ is to distinguish PD classification and Pdy only.

MCS-SP is a response to the absence of taxononomical system for the evaluation process, the formation of concepts and structured intervention towards athletes. The type of athlete category and its suitability with the type of intervention is described in Figure 1 [11].

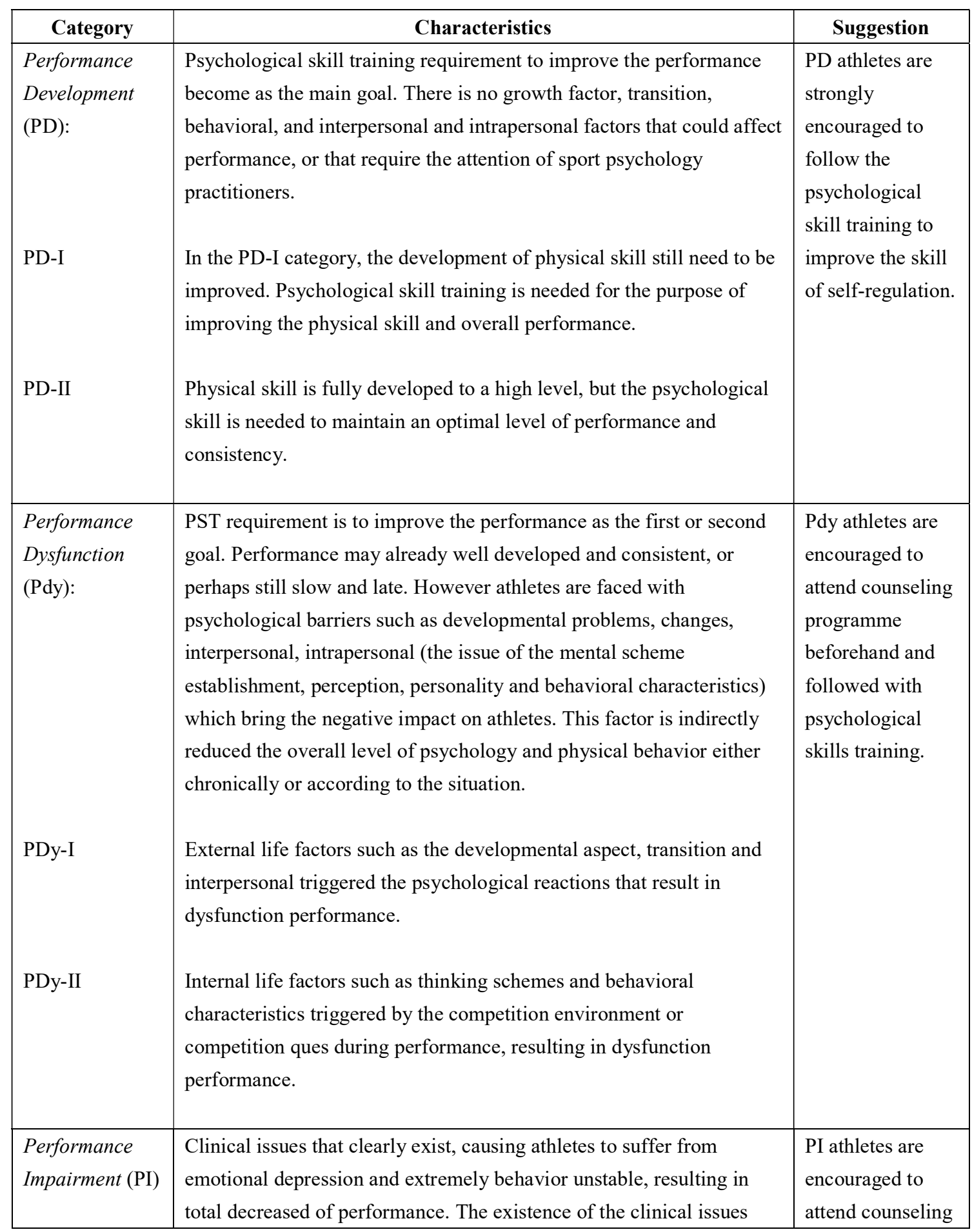






Fig.1. Classification of athletes category based on Multilevel Classification System for Sport Psychology (MCS-SP) [11] 
To ensure the success of the sport, athletes' performance must be viewed not only in terms of their physical but also psychological achievements. The function of the individual must always be examined and given appropriate intervention to preserve the health, physical and psychological wellbeing, optimum performance, and also as the mean to prevent, evaluate and reduce performance and personal difficulties. The effectiveness of PST to enhance the ideal level of athletes' performance can be more easily understood through the Integrated Model of Athletic Performance (IMAP) [11]. Based on IMAP model, athletes faced with the demands of internal and external processes that affect the willingness of their competitive behavior during the preparation phase. IMAP define the demands and the performance stimulus as a general and specific requirements to be met by the athlete based on the condition that they have to reach required standard at the end of the performance, while the standard itself is different based on the level of athletes. Therefore, in the preparatory phase, thinking schemes play a very important role as a general response to the demands of performance. Thinking schemes can activate the content of schemata based on the personal characteristics of the athlete, and it determines the athlete performance as functional or dysfunctional. Mental schemes controlling thought and behavior and operates like a radar that detects psychological threats and affects the behavior, thinking and affective [11].

During the presentation phase also, athletes' behavior is regulated by a feedback control system. Feedback control system is a kind of metacognitive processes when athletes identify the relevant aspects of his behavior and systematically customize them to reach the expected standard of behavior. This metacognitive process is equivalent to the concept of mindfulness that is "paying attention in a particular way; on purpose, in the present moment, and non-judgmentally" [13]; or flow and peak experience [14, 15]. Therefore, the ideal performance of functional athlete can be achieved if athletes possess an appropriate level of mindfulness skill during presentation phase [16].

Few studies suggested that there are limitations of the study if the subject is homogenous, which resulted in an increase of the minimum performance [12, 17, 18]. However, if taking into account differences based on MCS-SP, it was found that the performance improvement effects are more noticeable. Other study on the effectiveness of Mindfulness Aceptance Commitment (MAC) in sport performance enhancement, suggested if the study combined the 
overall performance improvement of athletes regardless of the treatment or MCS-SP category type, it seems that the performance improvement percent by MAC intervention is similar compared to the study on performance improvement using traditional methods of PST [11]. The study proposed that MAC intervention is more effective if carried out on athletes from the PD-I (Performance-Development I) and PD-II (Performance-Development II) categories which are not under clinical supervision [11].

MCS-SP also used to identify the effects of sub-clinical psychological difficulties towards the intervention ability of Mindfulness Acceptance Commitment (MAC) on the performance [19]. Before the intervention, MCS-SP was used to determine the experimental group. The results showed that the presence and absence of sub-clinical psychological difficulty really produce a moderator effect to the efforts of improving athletes' performance. Other study was conducted on the effectiveness of theraphy treatment in Observed and Experiential Integration (OEI) towards the major psychological barrier on the athletes' performance [20]. Subjects were selected among athletes students for the Performance Dysfunction (Pdy) category. The Pdy athletes showed that there are some sub-clinical issues faced by the athletes students. After five phases of data collection, it was found that the OEI therapy treatment, therapeutic relationship between the researcher and the subject, and the subject's perception is the key variable on the change of athlete performance.

Therefore, the current study was conducted to test the effectiveness of MCS-SP for athletes' performance functional evaluation among MASUM athletes at University Pendidikan Sultan Idris Malaysia. The aim of the study is to determine the classification of athletes, and to identify the level of athletes' performance in terms of mindfulness skills and thinking schemes. Based on the MCS-SP model, it is assumed that the Performance Development (PD) athletes showed a higher level of mindfulness compared to Performance Dysfunction (Pdy) athlete. In addition, it is also assumed that intrapersonal issue such as thinking scheme is more likely prominent among Pdy athletes compared to PD athletes. 


\section{RESEARCH METHODOLOGY}

\subsection{Subjects}

The subjects were athletes from Performance Development (PD) ( $\mathrm{n}=54)$ and Performance Dysfunction (Pdy) $(n=43)$ categories. Classification of athletes' performance function was obtained through the Performance Classification Questionnaire (PCQ). All the subjects were from UPSI MASUM athletes who participated in MASUM 2015 tournament. Of the total athlete, the number of male athletes was 70 (72.2\%), while female athletes were $27(27.8 \%)$. The average age of the overall athletes is $22.6(\mathrm{SD}=1.37)$. Whereas, the average years of involvement in sport since school period to university is 6:53 $(\mathrm{SD}=3.79)$.

\subsection{Instrument}

This study used Performance Classification Questionnaire (PCQ) [12] to distinguish athletes into the categories of Performance Development (PD) and Performance Dysfunction (Pdy). PCQ is a kind of self-assessment, which contains 10 Likert scale items. The scoring method is to add all the scores (items 5 and 7 shall be reversed). A score of less than 30 indicated the PD athletes, while a score of 30 and above is Pdy athletes. Cronbach's alpha to determine the internal reliability of the questionnaire for this study was 0.82 .

Five Facet Mindfulness Questionnaire (FFMQ) also has been used to measure mindfulness skill [21]. FFMQ is a kind of self-report contains 39 likert scale questions that measure the skills of mindfulness. There are five important factors in mindfulness skills, namely observing, describing, acting with awareness, nonjudging, and nonreactivity. The higher score reflects the ability of mindfulness. Reliability report showed that the Cronbach's alpha ranging from 0.75 to 0.91 [22]. FFMQ questionnaire contains a sufficient degree of validity [21]. FFMQ questionnaire translated into Bahasa Melayu by using the back to back translation.

Other than FFMQ, Young Schema Questionnaire (YSQ-S3) has also been used to measure thingking schemes [23]. YSQ-S3 contains 90 questions with answers of 6 points Likert scale starting from 1 (very inaccurate relating to myself) to 6 (very accurate relating to myself). Cronbach's alpha value for YSQ-S3 is also high ranging from 0.72 to 0.93 .YSQ-S3 is translated into Bahasa Melayu by using the back to back translation. 


\subsection{Procedure}

For the success of this study, the researchers obtained permission from the UPSI Sport Center to engage UPSI student who involved in MASUM 2015 sport tournaments as research subjects. Initially, only 100 athletes committed to involve in this study by giving consent verbally to fill out the questionnaire. However, three athletes who have demonstrated the characteristics of Performance Termination (PT) has been removed from the potential subjects list. Then, the remaining 97 athletes were given a questionnaire of Performance Classification Questionnaire (PCQ), Five Facet Mindfulness Questionnaire (FFMQ) and Young Schema Questionnaire (YSQ-S3).

\section{RESEARCH RESULT}

\subsection{Performance Function}

The first question in this study was to determine the frequency of the subject performance based on classification function. Data were analyzed using the number and percentage. Table 1 shows a total of $54(55.7 \%)$ athletes are from the Performance Development (PD) category while the rest are 43 (44.3\%) athletes from the category of Performance Dysfunction (Pdy).

Table 1. The frequency of the subject based on the performance of athletes.

\begin{tabular}{ll}
\hline Performance Function Category & Frequency \\
\hline Performance Development (PD) & $54(55.7 \%)$ \\
Performance Dysfunction (Pdy) & $43(44.3 \%)$ \\
\hline
\end{tabular}

\subsection{Mindfulness}

The second question in this study was to determine the mindfulness skill level for the whole subject. Data from Five Facet Mindfulness Questionnaire (FFMQ) were analyzed descriptively using mean and standard deviation. Table 2 shows the whole mean scores of mindfulness for the subject is at a moderate level. 
Table 2. Mean and standard deviation of the mindfulness skill level

\begin{tabular}{lccc}
\hline & \multicolumn{3}{c}{ Score } \\
\cline { 2 - 4 } Mindfulness Subscales & $\boldsymbol{n}$ & $\boldsymbol{M}$ & $\boldsymbol{S D}$ \\
\hline Observing & 97 & 29.45 & 5.11 \\
Describing & 97 & 28.46 & 5.16 \\
Acting with awareness & 97 & 25.75 & 7.84 \\
Nonjudging & 97 & 25.26 & 6.52 \\
Nonreactivity & 97 & 28.43 & 7.25 \\
Total Mindfulness & 97 & 21.23 & 5.44 \\
\hline
\end{tabular}

\subsection{Thingking Schemes}

The third question in this study was to determine thinking schemes level for the entire subjects. Data from the Young Schema Questionnaire (YSQ-S3) questionnaire were analyzed using mean and standard deviation [23]. Table 3 shows that all 18 types of thinking schemes exhibited by athletes of UPSI MASUM are at moderate level.

Table 3. Mean and standard deviation of thinking schemes

\begin{tabular}{lccc}
\hline & \multicolumn{3}{c}{ Score } \\
\cline { 2 - 4 } Elements of Thinking Scheme & $\boldsymbol{n}$ & $\boldsymbol{M}$ & $\boldsymbol{S D}$ \\
\hline 1. Emotional deprivation & 97 & 21.39 & 4.25 \\
2. Abandonment & 97 & 21.81 & 4.29 \\
3. Mistrust/abuse & 97 & 20.79 & 3.24 \\
4. Social isolation & & & \\
5. Defectiveness/shame & 97 & 17.15 & 3.04 \\
6. Failure & 97 & 17.38 & 2.87 \\
7. Dependence/incompetence & & & \\
\end{tabular}


8. Vulnerability to harm or illness

9. Enmeshment

10. Subjugation

11. Self-sacrifice

12. Emotional inhibition

13. Unrelenting standard

14. Entitlement

15. Insufficient self-control/self-discipline

16. Approval research

\subsection{Mindfulness skill based on performance function classification}

Based on the Multilevel Classification System for Sport Psychology (MCS-SP), it was assumed in the study that the PD athlete showed a higher level of mindfulness compared to Pdy athlete. Independent Samples T-Test is used to verify this assumption. There were a significant differences between group, $t(95)=2.998, p=0.03, d=0.60$, moderate effect size for observing skill; $t(95)=2.381, p=0.019, d=0.40$, small effect size for describing skill; $t(95)=2.897, p=0.05, d=0.60$, moderate effect size for nonjudging; $t(95)=2.689, p=0.08$, $d=0.80$, large effect size for nonreactivity; and finally $t(95)=3.625, p=0.000, d=0.80$, large effect size for the whole score of mindfulness. The result confirmed that the PD athletes were significantly prominent in terms of observing, describing, nonjudging, nonreactivity, and total mindfulness skill compared to Pdy athletes. 
Table 4. Mean scores for mindfulnes skills between groups

\begin{tabular}{lcccc}
\hline & \multicolumn{2}{c}{ Performance Functional } & \\
& \multicolumn{2}{c}{ Classification } & & \\
\cline { 2 - 3 } Mindfulness Subscales & PD & Pdy & $\boldsymbol{t}$ & $\boldsymbol{d}$ \\
\cline { 2 - 5 } Observing & $30.74 \pm 5.57$ & $27.84 \pm 3.96$ & $2.998^{*}$ & 0.60 \\
Describing & $29.52 \pm 5.62$ & $27.14 \pm 4.21$ & $2.381^{*}$ & 0.40 \\
Acting with awareness & $27.00 \pm 8.22$ & $24.20 \pm 7.12$ & 1.776 & 0.30 \\
Nonjudging & $26.91 \pm 6.29$ & $23.20 \pm 6.28$ & $2.897^{*}$ & 0.60 \\
Nonreactivity & $30.09 \pm 7.86$ & $26.35 \pm 5.85$ & $2.689^{*}$ & 0.60 \\
Total Mindfulness & $22.83 \pm 6.20$ & $19.21 \pm 3.43$ & $3.652^{*}$ & 0.80 \\
\hline
\end{tabular}

\subsection{Thinking schemes based on performance function classification}

This study also assumes that intrapersonal issues such as thinking schemes is more prevalent among Pdy athletes compared to PD athletes based on the Multilevel Classification System for Sport Psychology (MCS-SP) model. There are 18 thinking scheme sub-scales. The data were analyzed using Independent Samples T-Test to confirm this assumption. Table 5 shows that there were significant difference between groups in 17 sub-scales of thinking scheme, those are emotional deprivation, $t(95)=-8.636, p=0.000, d=1.00$, large effect size; abandonment, $t(95)=-7.735, p=0.000, d=1.00$, large effect size; social isolation, $t(95)=$ $-6.886, p=0.000, d=1.00$, large effect size; defectiveness/shame, $t(95)=-6.886, p=0.000, d$ $=1.00$, large effect size; failure, $t(95)=-3.818, p=0.000, d=0.80$, large effect size; dependence/incompetence, $\mathrm{t}(95)=-3.818, p=0.000, d=1.00$, large effect size; vulnerability to harm or illness, $t(95)=-5.750, p=0.000, d=1.00$, large effect size; enmeshment, $t(95)=$ -2.586, $p=0.011, d=0.50$, moderate effect size; subjugation, $t(95)=-7.170, p=0.000, d=$ 1.00 , large effect size; self-sacrifice, $t(95)=4.005, p=0.000, d=0.80$, large effect size; emotional inhibition, $t(95)=-11.428, p=0.000, d=2.0$, large effect size; unrelenting standard, $t(95)=3.829, p=0.00, d=0.7$, moderate effect size; and entitlement, $t(95)=5.023$, $p=0.000, d=1.00$, large effect size. The result confirmed that the Pdy athletes were more significantly prominent compared to PD athletes in terms of emotional deprivation, abandonment, social isolation, defectiveness/shame, failure, dependence/incompetence, 
vulnerability to harm or illness, enmeshment, subjugation, emotional inhibition, insufficient self-control/self-discipline, approval research, negativity/pessimism, and punitiveness. However, in term of self-sacrifice, unrelenting standard and entitlement elements, there were more prevalent towards PD compared to Pdy athletes.

Table 5. Mean scores for thinking schemes between groups

\begin{tabular}{|c|c|c|c|c|c|}
\hline & \multirow[b]{2}{*}{ Elements of Thinking Scheme } & \multicolumn{2}{|c|}{$\begin{array}{c}\text { Performance Functional } \\
\text { Classification }\end{array}$} & \multirow[b]{2}{*}{$t$} & \multirow[b]{2}{*}{$d$} \\
\hline & & PD & Pdy & & \\
\hline & Emotional deprivation & $18.89 \pm 3.32$ & $24.53 \pm 3.04$ & $-8.636^{*}$ & 1.00 \\
\hline 2. & Abandonment & $19.44 \pm 2.52$ & $24.79 \pm 4.22$ & $-7.735^{*}$ & 1.00 \\
\hline 3. & Mistrust/abuse & $21.20 \pm 3.46$ & $20.28 \pm 2.91$ & 1.402 & 0.30 \\
\hline 4. & Social isolation & $15.72 \pm 2.58$ & $18.95 \pm 2.63$ & $-6.886^{*}$ & 1.00 \\
\hline 5. & Defectiveness/shame & $15.90 \pm 2.31$ & $19.23 \pm 2.43$ & $-6.886^{*}$ & 1.00 \\
\hline 6. & Failure & $16.78 \pm 3.55$ & $19.30 \pm 2.78$ & $-3.818^{*}$ & 0.80 \\
\hline 7. & Dependence/incompetence & $13.98 \pm 2.63$ & $17.00 \pm 2.18$ & $-6.045^{*}$ & 1.00 \\
\hline 8. & Vulnerability to harm or illness & $15.00 \pm 2.74$ & $17.95 \pm 2.19$ & $-5.750 *$ & 1.00 \\
\hline 9. & Enmeshment & $12.65 \pm 2.92$ & $13.91 \pm 1.85$ & $-2.586^{*}$ & 0.50 \\
\hline 10. & Subjugation & $12.76 \pm 2.94$ & $16.56 \pm 2.07$ & $-7.170 *$ & 1.0 \\
\hline 11. & Self-sacrifice & $17.52 \pm 2.24$ & $15.72 \pm 2.14$ & $4.005^{*}$ & 0.80 \\
\hline 12. & Emotional inhibition & $11.98 \pm 2.49$ & $17.72 \pm 2.41$ & $-11.428^{*}$ & 2.0 \\
\hline 13. & Unrelenting standard & $17.46 \pm 1.65$ & $16.09 \pm 1.87$ & $3.829 *$ & 0.70 \\
\hline 14. & Entitlement & $17.57 \pm 2.35$ & $15.44 \pm 1.67$ & $5.023^{*}$ & 1.00 \\
\hline
\end{tabular}



15. Insufficient
$14.02 \pm 2.11$
$18.12 \pm 1.92$
$-9.903 *$
2.00
self-control/self-discipline

16. Approval research

17. Negativity/pessimism

18. Punitiveness
$16.33 \pm 2.91$

$14.50 \pm 2.14$

$13.57 \pm 1.72$
$18.63 \pm 2.52$

$-4.095 *$

0.80

$17.77 \pm 2.27$

$-7.272 *$

1.00

2.00

\section{DISCUSSION}

Based on descriptive studies, it is clearly show that the measuring tool of Performance Classification Questionnare (PCQ) are capable in determining the classification of Performance Development (PD) and Performance Dysfunction (Pdy) based on Multilevel Classification System for Sport Psychology (MCS -SP) model. As proposed, PCQ can be used to obtain information about the athlete performance [15]. PCQ had been used for the same purpose by other study for the selection of PD athlete as their research samples [24] [25]. Morever, few researchers had confirmed that the need to identify the athletes' performance function category is very important to ensure the appropriateness of PST intervention in performance enhancement $[11,15,19,20,25,26]$.

In addition, the study also found that mindfulness skills level of the entire subject is moderate. This study also supports the proposed model of MCS-PD SP that PD athletes should show higher mindfulness skill level than Pdy athletes. Based on the PD athlete criteria, the main issue of PD athletes is only related to the improvement of physical performance because athletes do not experience any significant problems in terms of development, behavioral changes, interpersonal and intrapersonal which could affect their physical performance. For PD athlete, mindfulness skills are needed to achieve peak performance because the functional of peak performance will be produced only when the process of self-assessment, focusing on internal and external threats, and focusings on the expected results of the performance is at minimal level. Therefore, PD athletes are those who suppose to achieved peak performance in sport $[14,15]$ and should have a high mindfulnes skills [16]. This is also supported by the 
results of another study which suggested that the feature of high mindfulness was associated with high performance [27].

Finally, the study also found that the level of thinking scheme for the entire subjects is moderate. However, the initial assumption that these intrapersonal issues should be more prominent among Pdy athlete compared to PD athlete was slightly contradicted with the proposed model of MCS-SP. The model explained that Pdy athletes not only has the level of performance that might already well developed and consistent, or perhaps still slow and late, however Pdy athletes also dealing with psychological barriers such as developmental problems, changes, interpersonal, intrapersonal (the issue of the thinking scheme establishment, perception, personality and behavioral characteristics) which affect the athletes negatively [15]. In fact, these characteristics of Pdy athlete are very different compared to PD athletes who should be free from the problem of development, behavior, interpersonal and intrapersonal issue that can affect their physical performance significantly. However, from the finding of this study, although athletes are categorized as PD, the tendency of having thinking scheme such as self-sacrifice, unrelenting standard and entitlement were higher than Pdy athlete. This was something that might be misinterpreted or over interpret that can cause affective reaction and behavioral frustration, anxiety, dysfunction performance and eventually withdraw from the sport [11]. Athletes who possess athlete's identity schemes that are too high and exclusive have a high probability of having a negative affective impact and implications of injury [28].

\section{ACKNOWLEDGEMENT}

This material is based upon work supported by the Universiti Pendidikan Sultan Idris Research Grant No. 2016-0019-106-01.

\section{REFFERENCES}

[1] Hardy L, Jones G, Gould D. Understanding psychological preparation for sport: Theory and practice of elite performers. New York: Wiley, 1996 
[2] Ravizza K. Reflections and insights from the field on performance enhancement consultation. In G. Tennenbaum (Ed.), The practice of sport psychology (pp. 197-216). Morgantown, WV: Fitness Information Technology, Inc, 2001

[3] Williams J M, Straub W F. (1998). Sport psychology: Past, present, future. In J. M. Williams (Ed.) Applied sport psychology. Personal growth to peak performance (3rd ed.) Mayfield, Mountain View, Calf, 1998, pp. 1-12

[4] Weinberg R S, Gould D. Foundations of sport and exercise psychology. (2nd ed.) United States of America: Human Kinetics, 2007

[5] Vealey S R. Mental Skills Training in Sport. In G. Tenenbaum, R. Eklund, R. Singer (Eds.), Handbook of sport psychology. New Jersey: Wiley, 2007

[6] Weinberg R S, Williams J, M. Integrating and implementing a psychological skills training program. In J. M. Williams (Ed.), Applied sport psychology: Personal growth to peak performance (347-377). Mountain View, CA: Mayfield Publishing Company, 2006

[7] Bond J. The provision of sport psychology services during competition tours. In G. Tenenbaum (Ed.), The practice of sport psychology Morgantown, WV: Fitness Information Technology, Inc, 2001, pp. 217-229

[8] Danish S J, Petitpas A J, Hale B D. Psychological interventions: A life developmental model. In S. Murphy (Ed.), Sport psychology interventions Champaign, IL: Human Kinetics, 1995, pp. $19-38$

[9] Gardner F L. Principles and practices of acceptance-based sport psychology. Grand rounds lecture presented at the Department of Psychiatry Grand Rounds at North Shore University Medical Center and Health System, Manhasset, NY, 2001

[10] Van Raalte J L, Brewer B. W. Exploring sport and exercise psychology, Washington, DC: American Psychological Association, 1996

[11] Gardner F L, Moore Z E. Clinical sport psychology. Champaign, IL: Human Kinetics, (2006)

[12] Gardner F L, Wolanin A T, Moore Z E. Mindfulness-Acceptance-Commitment (MAC) based performance enhancement for Division I athletes: A preliminary investigation. Manuscript submitted for publication, 2005

[13] Kabat-Zinn J. Wherever you go, there you are. New York: Hyperion, 1994 
[14] Csikszentimihalyi M. Flow: The psychology of optimal experience. New York: Harper and Row, 1990

[15] Gardner F L, Moore Z E. A Mindfulness-Acceptance-Commitment (MAC) based approach to athletic performance enhancement: Theoretical considerations. Behavior Therapy, 2004, 35, pp. 707-723

[16] Gardner F L, Moore Z E. The psychology of enhancing human performance: The Mindfulness-Acceptance-Commitment (MAC) approach. New York: Springer Publishing, 2007

[17] Martin G L, Toogood A. Cognitive and behavioral components of a seasonal performance skills training program for figure skaters. Cognitive and Behavioral Practice, 1997, 4, pp. 383-404

[18] Wolanin A T. Mindfulness-Acceptance-Commitment (MAC) based performance enhancement for Division I collegiate athletes: A preliminary investigation (Doctoral dissertation, La Salle University, 2003). Dissertation Abstracts International-B, 2005. pp. 3735-3794

[19] Wolanin A T, Schwanhausser L A. Psychological functioning as a moderator of the MAC approach to performance enhancement. Journal of Clinical Sport Psychology, 2010, 4, pp. $312-322$

[20] Wall J M, Kwee J L, McDonald M J, Bradshaw, R A. Removing Barriers to Athlete PerformanceEnhancement: A Hermeneutic Case Studyof Observed and Experiential Integration, Journal of Clinical Sport Psychology, 2014, 8, pp. 378-399

[21] Baer R A, Smith G, Hopkins J, Krietemeyer J, Toney L. Using self-report assessment methods to explore facets of mindfulness. Assessment, 2006, 13, pp. 27-45

[22] Hasker S M. Evaluation of the mindfulness-acceptance-commitment (MAC) approach for enhancing athletic performance (Unpublished doctoral dissertation). Indiana University of Pennsylvania, 2010

[23] Young J E, Klosko J S, Weishaar M E. Schema therapy: A practitioner's guide. New York: Guilford Press, 2003 
[24] Schwanhausser L. Application of the Mindfulness-Acceptance-Commitment (MAC) protocol with an adolescent springboard diver: The case of Steve. Journal of Clinical Sport Psychology, 2009, 3, pp. 377-396

[25] Wolanin A T. (2005). Mindfulness-Acceptance-Commitment (MAC) based performance enhancement for Division I collegiate athletes: A preliminary investigation (Unpublished doctoral dissertation). La Salle University.

[26] Martin G L, Toogood A. Cognitive and behavioral components of a seasonal performance skills training program for figure skaters. Cognitive and Behavioral Practice, 1997, 4, pp. 383-404

[27] Gooding A, Gardner F L. An Investigation of the Relationship between Mindfulness, Preshot Routine, and Basketball Free Throw Percentage. Journal of Clinical Sport Psychology, 2009, 3(4), 303-319

[28] Horton R S, Mack D E. Athlete identity in marathon runners: Functional focus or dysfunctioanl commitment? Journal of Sport Behavior, 2000, 23, 101-119

\section{How to cite this article:}

Mohamad Khalid N. H., Mohd Shariff A. R. and Ahmad Y. The effectiveness of multilevel classification system for Sport Psychology (MCS-SP) Model for athletes performance functional evaluation. J. Fundam. Appl. Sci., 2017, 9(6S), 1355-1371. 